Эрлих А. А. ${ }^{1}$, Ажинибалаева Ж. В. ${ }^{2}$, Киселев А. Р. ${ }^{3}$, Посненкова О. М. ${ }^{3}$, Аупияков А. В. ${ }^{2,4}$ и все участники регистра «РЕКОРА-3»*

${ }^{1}$ ФББУ «ФеАеральный научно-клинический центр физико-химической медицины» ФМБА России, Москва

${ }^{2}$ ГБУЗ «Самарский областной клинический карАиологический Аиспансер» МинзАрава РФ, Самара

${ }^{3}$ ФББОУ ВО «Саратовский госуАарственный медицинский университет им. В. И. Разумовского» МинзАрава РФ, Саратов

${ }^{4}$ ФББОУ ВО «Самарский госуАарственный медицинский университет» МинзАрава РФ, Самара

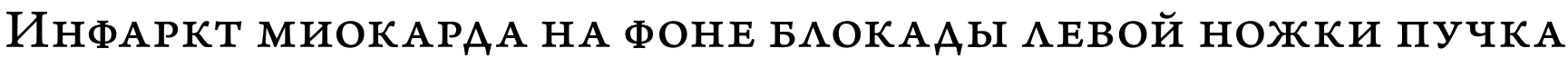 ГИСА В РЕГИСТРЕ РЕКОРА-3: ОСОБЕННОСТИ ВЕАЕНИЯ И ПРОГНОЗ
}

\author{
DOI: $10.18087 /$ cardio.2017.7.10002 \\ КАючевые слова: острый коронарный синдром, инфаркт миокарАа, блокада мевой ножки пучка Гиса, прогноз. \\ Ссылка дял цитирования: Эрлих А.А., Ажинибалаева Ж. В., Киселев А.Р., Посненкова О. М., Аупляков А.В. \\ и все участники регистра «РЕКОРА-3»*. Инфаркт миокарда на фоне блокады мевой ножки пучка \\ Гиса в регистре РЕКОРА-3: особенности ведения и прогноз. Кардиология. 2017;57(7):20-26.
}

Резюме

Цель исследования. Изучение прогностического значения блокады мевой ножки пучка Гиса (БАНПГ) у пациентов с верифицированным инфарктом миокарда (ИМ) в клинической практике. Материал и методы. Настоящий анализ выполнен на материалах, полученных в ходе провеАения Российского наблюАательного регистра острого коронарного синарома (ОКС) РЕКОРА-3. В регистр вкАючались все последовательно госпитализированные пациенты, у которых в стационарах-участниках при поступлении бымо преАположено наличие ОКС. Всего включены 2368 пациентов с ОКС, из них у 91 (3,84\%) на электрокардиограмме при поступлении была выявлена БАНПГ: «новая» БАНПГ опредемялась у 25 (27,4\%), «старая» у $28(30,8 \%)$ и «неопредеменной Аавности» у 38 (41,8\%) пациентов. Аиагноз ИМ был верифицирован у 871 пациента, из них 823 пациента не имели признаков БАНПГ, а у 48 (5,5\%) она имелась. Результаты. Пациенты с ИМ в сочетании с БАНПГ на ЭКГ оказались Аостоверно старше (70,5 гоАа против 64,0 гоАа; $\mathrm{p}=0,011)$, чаще имели в анамнезе ИМ и инсульт, а также стенокардию напряжения, симптомы хронической сердечной недостаточности и патологию почек. Жалобы на одышку/удушье встречались у пациентов с БАНПГ почти в 2 раза чаще. На Аогоспитальном этапе пациенты с БАНПГ Аостоверно реже получали терапию ацетилсалициловой кислотой (АСК), клопидогрелом, $\beta$-адреноблокаторами. Группы статистически значимо различались по фракции выброса на момент поступления - 44\% в группе пациентов с БАНПГ против $52 \%$ у пациентов без БАНПГ $(\mathrm{p}<0,001)$. Выраженная коморбидность у пациентов с БАНПГ проявилась и в необходимости более частого использования искусственной вентиляции кегких (ИВА) и временной электрокардиостимуляции. В случае развития ИМ на фоне БАНПГ пациенты имели меньше шансов на выбор реперфузионной стратегии - 52,1\% пациентов с Б $\Lambda$ НПГ против $85 \%$ в группе без БАНПГ (р<0,001). На коронарографию были направлены только 37,5\% пациентов с БАНПГ против 64,1\% в группе без БАНПГ ( $<<0,001)$, а первичное чрескожное коронарное вмешательство выполнено только у $25 \%$ пациентов с БАНПГ против 46,4\% без таковой (р=004). Пациенты с ИМ на фоне БАНПГ имели более чем Авукратный риск смерти в стационаре $(14,6 \%$ против 6,3\%; p<0,027), без Аостоверных размичий межАу «новой» и «старой» блокаАами. По результатам многофакторного регрессионного анализа Кокса, независимыми факторами неблагоприятного прогноза оказались необходимость проведения ИВ $\Lambda$, потребность в прессорных препаратах в первые 24 ч и в последующем, а также частота сердечных сокращений на 2-е сутки. Заключение. Высокая метальность у пациентов с ИМ, включенных в российский регистр ОКС РЕКОРА-3, на фоне БАНПГ обусловлена не просто присутствием на ЭКГ БАНПГ, а более старшим возрастом, тяжестью состояния при поступлении и большим количеством сопутствующих заболеваний.

Erlikh A. D. ${ }^{1}$, Dzhinibalaeva Zh. B. ${ }^{2}$, Kiselev A. R. ${ }^{3}$, Posnenkova O. M. ${ }^{3}$, Duplyakov D. V., ${ }^{2,4}$ and the RECORD-3 Registry Participants

${ }^{1}$ Federal Scientific-Clinical Centrum of Physico-Chemical Medicine of Federal medico-biological Agency RF, Moscow, Russia

${ }^{2}$ Samara Regional Cardiology Dispensary, Samara, Russia

${ }^{3}$ Saratov State Medical University named after V.I. Razumovsky, Saratov, Russia

${ }^{4}$ Samara State Medical University, Samara, Russia

\section{MYOCARDIAL INFARCTION AT THE BACKGROUND OF LEFT BUNDLE BRANCH BLOCK IN THE RECORD-3 Registry - Management and Prognosis}

Keywords: acute coronary syndrome; myocardial infarction; left bundle brunch block; prognosis.

For citation: Erlikh A.D., Dzhinibalaeva Zh.B., Kiselev A.R., Posnenkova O.M., Duplyakov D. V. Myocardial Infarction at the Background of Left Bundle Branch Block in the RECORD-3 Registry-Management and Prognosis. Kardiologiia. 2017;57(7):20-26. 


\section{SUMMARY}

Purpose. To study prognostic value of left bundle brunch block (LBBB) in patients with verified myocardial infarction in real clinical practice. Material and methods. This analysis has been based on data from the RECORD-3 registry. This registry enrolled consecutive patients hospitalized in participating centers with suspected acute coronary syndrome. Among 2368 included patients 91 (3.84\%) had LBBB on admission ECG ("new" in 25 [27.4\%], "old" in 28 [30.8\%]), and of "undetermined duration" in 38 [41.8\%]). Myocardial infarction (MI) was verified in 871 patients, 48 of them (5.5\%) had LBBB. Results. MI patients with compared with those without LBBB were significantly older (70.5 vs. 64 years, $\mathrm{p}=0.011)$, more often had history of MI and cerebral catastrophes, effort angina, symptoms of chronic heart failure and renal pathology. Patients with LBBB twice more often complained of dyspnea/suffocation and had significantly lower mean ejection fraction ( $44 \mathrm{vs} 52 \%, \mathrm{p}=0.001)$. At prehospital stage, they less often received aspirin, clopidogrel, $\beta$-adrenoblockers. Patients with LBBB more often required artificial pulmonary ventilation (APV) and temporary cardiac pacing, and were less often subjected to reperfusion strategy ( 52.1 vs. $85 \%, \mathrm{p}<0.001)$. Coronary angiography was carried out in 37.5 and $64.1 \%$ $(\mathrm{p}<0.001)$, primary percutaneous coronary intervention was performed in 25 and $46.4 \%(\mathrm{p}=0.0004)$ of patients in groups with and without LBBB, respectively. Patients with LBBB had more than 2 times higher risk of death during hospitalization (14.6 vs. 6.3\%, $\mathrm{p}<0.027$ ), without significant difference between "new" and "old" block. Multifactorial regression analysis revealed the following independent factors of unfavorable prognosis: necessity of APV, requirement in pressor drugs during first 24 hours and thereafter, heart rate on day two. Conclusion. High hospital mortality of patients with MI with LBBB was due to not simply the presence of LBBB on ECG but older age, severity of condition at admission, and high number of concomitant diseases.

$\mathrm{B}^{\mathrm{e}}$ едение пациентов с инфарктом миокарда (ИМ), имеющих на электрокарАиограмме (ЭКГ) блокаАу мевой ножки пучка Гиса (БАНПГ), преАставляет сложности Аля практикующих врачей. Она регистрируется на ЭКГ в среАнем у $5 \%$ пациентов с ИМ [1-3]. Пациенты с БАНПГ характеризуются более тяжелым течением заболевания и имеют неблагоприятный краткосрочный прогноз [2-5]. В ряде исслеАований показано, что качество оказания помощи пациентам с ИМ на фоне БАНПГ хуже, чем пациентам без нее [4-10].

Цель исследования: изучение прогностического значения БАНПГ у пациентов с верифицированным ИМ в кАинической практике.

\section{Материам и методы}

Настоящий анализ выполнен на материалах, полученных в ходе проведения российского регистра острого коронарного синарома (ОКС) PЕКОРА-3. Это было наблюАательное исследование, организованное по инициативе самих его участников. В регистр включали всех последовательно госпитализированных пациентов, у которых в стационарах-участниках при поступлении было преАположен ОКС. Включение в регистр проводили в течение 1 мес (с марта по апрель 2015 г.) в 47 стационарах 37 городов из 21 региона России. По принципам организации регистр PЕКОРА-3 быи схож спреАЫАущими регистрами - РЕКОРА и РЕКОРА-2, а по схеме вкАючения - с регистром РЕКОРА (в котором вкмючение также Алилось 1 мес), чем с регистром РЕКОРА-2 (гАе в кажАом стационаре кажАый месяц включали 10-30 последовательных пациентов с ОКС).

Всего в регистр РЕКОА-3 быми включены 2368 пациентов с ОКС, из них у 91 (3,84\%) на ЭКГ при поступлении выявлена БАНПГ: «новая» БАНПГ определялась у $25(27,4 \%)$, «старая» - у $28(30,8 \%)$ и «неопределенной Аавности» у $38(41,8 \%)$ пациентов. «Новой» считами БАНПГ, если у пациента имелись ЭКГ Аля сравнения, на которых она ранее не регистрировалась; «старая» БАНПГ подразумевала нахичие блокаАы на ЭКГ, снятых ранее; «неопределенной Аавности» - когАа Аостоверно срок появления БАНПГ установить бымо невозможно.

При поступлении у 52 (57,1\%) пациентов из 91 был установлен Аиагноз ОКС с подъемом сегмента ST на ЭКГ (ОКСпSТ), а у 39 (42,9\%) - ОКС без подъема сегмента ST (ОКСбпST) (табц. 1).

Аля изучения прогностического значения БАНПГ из всей когорты пациентов с ОКС, включенных в регистр, мы выбрали только пациентов с верифицированным Аиагнозом ИМ, подтвержАенным соответствующей Аинамикой кардиоспецифических ферментов (тропонин), а также объеАинили пациентов с «новой» и БАНПГ «неизвестной Аавности».

Всего Аиагноз ИМ бым верифицирован у 871 пациента, из них 823 не имеми признаков БАНПГ, а у 48 она присутствовала (см. табл.1). Среди всех вкцючен-

Таблица 1. Частота выявления БАНПГ у пациентов с ОКС и ИМ

\begin{tabular}{|c|c|c|c|c|c|c|c|c|}
\hline \multirow{3}{*}{ ОКС/ИМ } & \multicolumn{4}{|c|}{ OKCпST } & \multicolumn{4}{|c|}{ ОКСбпST } \\
\hline & \multicolumn{2}{|c|}{ БАНПГ } & \multicolumn{2}{|c|}{ без БАНПГ } & \multicolumn{2}{|c|}{ БАНПГ } & \multicolumn{2}{|c|}{ без БАНПГ } \\
\hline & абс. & $\%$ & aбc. & $\%$ & абс. & $\%$ & абс. & $\%$ \\
\hline OKC & 52 & 5,99 & 815 & 94,01 & 39 & 2,61 & 1455 & 97,39 \\
\hline ИМ & 30 & 6,09 & 463 & 93,91 & 18 & 4,80 & 360 & 95,20 \\
\hline
\end{tabular}

3Аесь и в таблице 2-8: ОКС - острый коронарный синдром; ИМ - инфаркт миокарАа; БАНПГ - блокада мевой ножки пучка Гиса; OKCпST - OKC с подъемом сегмента ST; OКСбпST - OKC без подъема сегмента ST. 
ных пациентов с ОКСпST окончательный диагноз ИМ был установлен у 493 (56,9\%). При этом на фоне БАНПГ окончатемьный Аиагноз ИМ был установлен у $30(57,7 \%)$, а без БАНПГ - у $463(56,8 \%)$ пациентов.
Среди пациентов, госпитализированных с ОКСбпSТ, ИМ быи подтвержАен у $378(25,3 \%)$, из них в группе пациентов с БАНПГ у $18(46,2 \%)$, без БАНПГ у $360(24,7 \%)$.

Таблица 2. Исходные характеристики пациентов с ИМ в сочетании с БАНПГ и без нее

\begin{tabular}{|c|c|c|c|c|c|}
\hline \multirow{2}{*}{ Показатемь } & \multicolumn{2}{|c|}{ 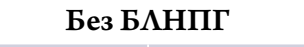 } & \multicolumn{2}{|c|}{ БАНПГ } & \multirow{2}{*}{$\mathbf{p}$} \\
\hline & $\mathbf{n}$ & $\%$ & $\mathbf{n}$ & $\%$ & \\
\hline Возраст, годы* & \multicolumn{2}{|c|}{$64(56 ; 75)$} & \multicolumn{2}{|c|}{$70,5(60 ; 77,5)$} & 0,011 \\
\hline Пом (муж) & 544 & 66,3 & 26 & 54,2 & 0,341 \\
\hline ИМ в анамнезе & 230 & 28,5 & 23 & 50,0 & 02 \\
\hline Стенокардия в анамнезе & 415 & 52,1 & 33 & 71,7 & 0,010 \\
\hline $\mathrm{XCH} \mathrm{в} \mathrm{анамнезе}$ & 314 & 40,7 & 31 & 70,5 & $<01$ \\
\hline Артериальная гипертензия & 668 & 84,8 & 41 & 87,2 & 0,647 \\
\hline ХПН в анамнезе & 25 & 3,5 & 4 & 11,4 & 0,019 \\
\hline НМК/ТИА в анамнезе & 55 & 6,8 & 7 & 15,2 & 0,032 \\
\hline MA & 98 & 12,2 & 10 & 21,7 & 0,059 \\
\hline постоянная & 54 & 6,6 & 5 & 10,4 & 0,451 \\
\hline пароксизмамьная & 85 & 10,3 & 5 & 10,4 & 0,988 \\
\hline Курение & 263 & 33,6 & 12 & 27,3 & 0,384 \\
\hline СА в анамнезе & 148 & 18,2 & 13 & 27,7 & 0,108 \\
\hline Периферические артерии & 107 & 15,4 & 8 & 22,2 & 0,271 \\
\hline \multicolumn{6}{|c|}{ КАинические проявмения при поступмении } \\
\hline Боль/Аискомфорт в грудной киетке & 756 & 91,9 & 42 & 87,5 & 0,290 \\
\hline ОАышка/удушье & 318 & 38,6 & 32 & 66,7 & $<0,001$ \\
\hline Слабость & 440 & 53,5 & 30 & 62,5 & 0,223 \\
\hline Сердцебиение & 103 & 12,5 & 10 & 20,8 & 0,096 \\
\hline Остановка кровообращения/синкопе & 17 & 2,1 & 3 & 6,3 & 0,060 \\
\hline Бессимптомно & 4 & 0,5 & 1 & 2,1 & 0,155 \\
\hline ИВ $\Lambda$ & 43 & 5,3 & 8 & 16,7 & 0,001 \\
\hline Временная ЭКС & 10 & 1,2 & 3 & 6,3 & H.A. \\
\hline
\end{tabular}

* - данные преАставлены в виде медианы (25-й процентиль; 75-й процентиль).

3Аесь и в табл. 3-10: НМК - нарушение мозгового кровообращения; ТИА - транзиторная ишемическая атака; МА - мерцательная аритмия; ИВ $\Lambda$ - искусственная вентимяция мегких; ЭКС - эмектрокарАиостимумяция; н.А. - неАостоверно.

Таблица 3. Аабораторно-инструментальные данные пациентов с ИМ в сочетании с БАНПГ и без нее

\section{Показатемь}

САА при поступлении, мм рт. ст.

ААА при поступнении, мм рт. ст. ЧСС при поступмении, уА/мин САА, 2-е сутки, мм рт. ст.

ААА, 2-е сутки, мм рт. ст.

ЧСС, 2-е сутки, УА/мин

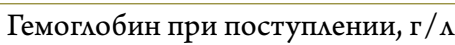

Гемоглобин (минимум), г/

Гематокрит при поступлении, \%

Гематокрит (минимум), \%

Тромбоциты, $10^{9} / \Lambda$

ГАюкоза при поступлении, ммоль $/ \Lambda$

ГАюкоза натощак, ммоль $/ \Lambda$

Креатинин при поступмении, мкмоль $/ \Lambda$

Креатинин (максимально), мкмоль $/ \Lambda$

$\Phi B, \%$
Без БАНПГ

\begin{tabular}{|c|c|c|c|c|c|c|}
\hline МеАиана & $\begin{array}{c}\text { 25-й } \\
\text { процентимь }\end{array}$ & $\begin{array}{c}\text { 75-й } \\
\text { процентимь }\end{array}$ & Медиана & $\begin{array}{c}25-и ̆ \\
\text { процентимь }\end{array}$ & $\begin{array}{c}\text { 75-й } \\
\text { процентимь }\end{array}$ & p \\
\hline 140 & 120 & 150 & 133,50 & 117,50 & 150 & 0,430 \\
\hline 80 & 75 & 90 & 80 & 70 & 90 & 0,471 \\
\hline 78 & 70 & 88 & 88,50 & 76 & 108,50 & $<01$ \\
\hline 120 & 110 & 134 & 1300 & 120 & 140 & 0,020 \\
\hline 72 & 70 & 80 & 80 & 70 & 80 & 08 \\
\hline 70 & 64 & 78 & 77 & 70 & 90 & $<01$ \\
\hline 140 & 126 & 151 & 139 & 128,50 & 150 & H.A. \\
\hline 131 & 118 & 143 & 130 & 115 & 143 & H.A. \\
\hline 41 & 36,55 & 44,65 & 40 & 35,20 & 44,40 & H.A. \\
\hline 38,3 & 34 & 42 & 37 & 32,4 & 42,3 & H.A. \\
\hline 219 & 145 & 274 & 215 & 146 & 276 & H.A. \\
\hline 6,70 & 5,50 & 8,50 & 6,65 & 5 & 11,90 & H.A. \\
\hline 5,50 & 4,90 & 6,50 & 5,40 & 4,90 & 8 & H.A. \\
\hline 90 & 78 & 115 & 93,50 & 85 & 123 & H.A. \\
\hline 99 & 86 & 131 & 110 & 87 & 131 & H.A. \\
\hline 52 & 45 & 57 & 44 & 38 & 52,5 & $<01$ \\
\hline
\end{tabular}


Статистическую обработку Аанных проводими с использованием программного пакета Statistica 6.0. Аанные представлены в виде частот (в процентах) амя качественных переменных и медианы с квартильным диапазоном - Me (25\%; 75\%) - аля количественных переменных. Сравнение групп по количественным переменным выполняли на основе критерия Манна-Уитни, по качественным - на основе критерия t. Выявление клинических факторов неблагоприятного прогноза проводили с использованием многомерной модели Кокса. Уровень значимости статистических размичий принимали как $\mathrm{p}<0,05$.

\section{Резумьтаты}

Пациенты с ИМ в сочетании с БАНПГ на ЭКГ оказались достоверно старше (70,5 гоАа против 64,0 гоАа; $\mathrm{p}=0,011)$, чаще имели в анамнезе ИМ и мозговые катастрофы, а также стенокардию напряжения, симптомы хронической серАечной недостаточности $(\mathrm{CH})$ и патомогию почек (табл.2). Жалобы на одышку/удушье встречались у пациентов с БАНПГ почти в 2 раза чаще, и это бымо их еАинственным отличием по клинической картине течения ИМ.

При поступмении значения САА и ААА Аостоверно не размичались межАу изучаемыми группами, оАнако у пациентов с БАНПГ сохранямись достоверно более высокие уровни АА на 2-й Аень госпитализации. Кроме того, ЧСС как в день поступления, так и на 2-е сутки у них оказались Аостоверно выше (табц.3). Группы статистически значимо отличались по ФВ на момент поступления - 44\% в группе пациентов с БАНПГ против $52 \%$ у пациентов без Б $\Lambda$ НПГ $(\mathrm{p}<0,001)$. Выраженная коморбидность у пациентов с БАНПГ проявилась и в необходимости более частого использования искусственной вентимяции мегких (ИВ $\Lambda$ ) и временной электрокардиостимумяции (см. табл.2).
В пиане медикаментозной терапии на госпитальном этапе (в 1-е сутки) статистически значимых размичий

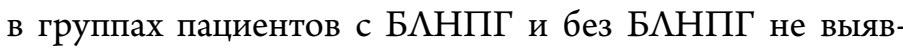
мено (табл.4). ОАнако на догоспитальном этапе пациенты с БАНПГ Аостоверно реже покучали терапию ацетилсалициловой кислотой (АСК), клопидогрелом, $\beta$-аАреноблокаторами.

В скучае развития ИМ на фоне БАНПГ пациенты имеки меньше шансов на выбор реперфузионной стратегии $52,1 \%$ при БАНПГ против $85 \%$ в группе без БАНПГ $(\mathrm{p}<0,001)$, причем за счет более реАкого проведения ЧКВ (табл.5). На КГ были направмены только 37,5\% пациентов с БАНПГ против 64,1\% в группе без БАНПГ $(\mathrm{p}<0,001)$, а первичное ЧКВ выполнено только у $25 \%$ пациентов с БАНПГ против 46,4\% (p=004). При этом ЧКВ в группе пациентов с «новой» БАНПГ было проведено у $28,7 \%$, среди пациентов со «старой» Б $\Lambda$ НПГ у $3,6 \%$ (табл. 6).

В группе пациентов с ИМ с БАНПГ частота возникновения таких небцагоприятных исходов, как развитие новой $\mathrm{CH}$, отека мегких, кардиогенного шока, а также остановки кровообращения, во время пребывания больных в стационаре оказалась почти в 3 раза выше, чем в группе без БАНПГ (табл.7), а острого нарушения мозгового кровообращения - почти в 6 раз (6,4\% против $1,2 \% ; \mathrm{p}=0,004)$.

Пациенты с ИМ на фоне БАНПГ имели более чем Авукратный риск метального исхода за время пребывания в стационаре (14,6\% против 6,3\%; p <0,027), без достоверных различий межАу «новой» и «старой» блокаАами (табл. 8).

При проведении регрессионного анализа факторами риска развития неблагоприятного исхода в периоА пребывания больного в стационаре стали класс по Killip $(\mathrm{p}<0,01)$, постоянная форма мерцательной аритмии,

Таблица 4. Медикаментозная терапия пациентов с ИМ в группах с БАНПГ или без БАНПГ

\begin{tabular}{|c|c|c|c|c|c|}
\hline \multirow{2}{*}{ Показатемь } & \multicolumn{2}{|c|}{ Без БАНПГ } & \multicolumn{2}{|c|}{ БАНПГ } & \multirow[b]{2}{*}{$\mathbf{p}$} \\
\hline & $\%$ & aбc. & $\%$ & абс. & \\
\hline АСК на догоспитальном этапе & 72,4 & 547 & 50 & 23 & 0,001 \\
\hline АСК в первые 24 ч в больнице & 93,8 & 760 & 91,7 & 44 & 0,549 \\
\hline Кнопидогрем на догоспитальном этапе & 57,3 & 458 & 37,5 & 18 & 0,007 \\
\hline Клопидогрем в первые 24 ч в больнице & 74,8 & 602 & 85,1 & 40 & 0,111 \\
\hline НФГ внутривенно на Аогоспитальном этапе & 39,6 & 310 & 36,2 & 17 & 0,637 \\
\hline НФГ внутривенно в первые 24 ч в стационаре & 48 & 388 & 39,1 & 18 & 0,244 \\
\hline Эноксапарин в первые 24 ч в стационаре & 13,4 & 108 & 17,4 & 8 & 0,445 \\
\hline Фондапаринукс в первые 24 ч в стационаре & 7,7 & 62 & 17,4 & 8 & 0,020 \\
\hline Ингибиторы АПФ в первые 24 ч в больнице & 77,9 & 624 & 85,4 & 41 & 0,220 \\
\hline$\beta$-ААреноблокаторы внутрь на Аогоспитальном этапе & 20,4 & 157 & 4,3 & 2 & 0,007 \\
\hline$\beta$-ААреноблокаторы внутрь в первые 24 ч в стационаре & 83,3 & 669 & 74,5 & 35 & 0,118 \\
\hline Прессорные препараты на догоспитальном этапе & 3,5 & 27 & 6,7 & 3 & 0,270 \\
\hline Прессорные препараты в первые 24 ч & 6,6 & 53 & 13,3 & 6 & 0,084 \\
\hline Прессорные препараты после 24 ч & 4,5 & 36 & 6,7 & 3 & 0,494 \\
\hline
\end{tabular}

АСК - ацетилсалицимовая кислота; НФГ - нефракционированный гепарин; АПФ - ангиотензинпревращающий фермент. 
Таблица 5. Реперфузионная терапия пациентов с ИМ в группах с БАНПГ и без БАНПГ

\begin{tabular}{|c|c|c|c|c|c|}
\hline \multirow[t]{2}{*}{ Показатемь } & \multicolumn{2}{|c|}{$\begin{array}{c}\text { Без } \\
\text { БАНПГ }\end{array}$} & \multicolumn{2}{|c|}{ БАНПГ } & \multirow[t]{2}{*}{$\mathbf{p}$} \\
\hline & $\%$ & абс. & $\%$ & абс. & \\
\hline $\begin{array}{l}\text { Выбор реперфузионной } \\
\text { стратегии }\end{array}$ & 85 & 697 & 52,1 & 25 & $<0,001$ \\
\hline КГ & 64,1 & 525 & 37,5 & 18 & $<0,001$ \\
\hline Поражение ствола $\Lambda$ КА & 61,5 & 495 & 37,5 & 18 & 0,001 \\
\hline Первичное ЧКВ & 46,4 & 382 & 25 & 12 & 0,004 \\
\hline 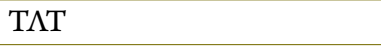 & 20,9 & 172 & 14,6 & 7 & 0,148 \\
\hline Без ТАТ из-за ОКСбпSТ & 37,4 & 308 & 39,6 & 19 & 0,764 \\
\hline $\begin{array}{l}\text { Без ТАТ } \\
\text { из-за позАнего поступмения }\end{array}$ & 11,8 & 97 & 12,5 & 6 & 0,882 \\
\hline
\end{tabular}

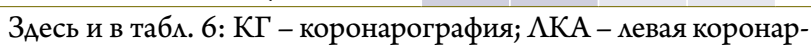
ная артерия; ЧКВ - чрескожное коронарное вмешательство; $\mathrm{T} \Lambda \mathrm{T}$ - тромболитическая терапия.

Таблица 6. Реперфузионная терапия в зависимости от Аавности БАНПГ

\begin{tabular}{|c|c|c|}
\hline $\begin{array}{c}\text { Реперфузионная } \\
\text { терапия, \% }\end{array}$ & $\begin{array}{l}\text { «Новая» } \\
\text { БАНПГ }\end{array}$ & $\begin{array}{c}\text { «Старая» } \\
\text { БАНПГ }\end{array}$ \\
\hline КГ & 42,86 & 21,4 \\
\hline ЧКВ & 28,57 & 3,6 \\
\hline $\mathrm{T} \Lambda \mathrm{T}$ & 14,3 & 3,6 \\
\hline
\end{tabular}

поражение периферических артерий $(\mathrm{p}=0,012)$, хроническая почечная недостаточность в анамнезе $(\mathrm{p}=0,013)$, ЧСС на 2-е сутки, необходимость проведения ИВ $\Lambda$ $(\mathrm{p}<0,01)$ и иноторопной поААержки При поступмении и в последующие сутки (табл. 9). При этом такие факторы, как возраст пациента, Аиагноз ОКСпSТ при поступлении, наличие хронической $\mathrm{CH}$, артериальной гипертонии, сахарного диабета, стенокардии в анамне-
Таблица 7. Неблагоприятные исходы в период пребывания в стационаре у пациентов с ИМ в группах с БАНПГ и без БАНПГ

\begin{tabular}{|c|c|c|c|c|c|}
\hline \multirow{2}{*}{ Показатемь } & \multicolumn{2}{|c|}{ Без БАНПГ } & \multicolumn{2}{|c|}{ БАНПГ } & \multirow{2}{*}{$\mathbf{p}$} \\
\hline & $\%$ & абс. & $\%$ & абс. & \\
\hline «Новая» $\mathrm{CH}$ & 8,8 & 71 & 22,7 & 10 & 0,002 \\
\hline Отек мегких & 6,2 & 50 & 17,8 & 8 & 0,003 \\
\hline КарАиогенный шок & 5,4 & 44 & 15,6 & 7 & 0,005 \\
\hline Стойкая ЖТ/ФЖ & 2,7 & 22 & 0 & 0 & 0,262 \\
\hline $\begin{array}{l}\text { Остановка } \\
\text { кровообращения }\end{array}$ & 5,6 & 45 & 13,3 & 6 & 0,033 \\
\hline «Новое» ОНМК & 1,2 & 10 & 6,4 & 3 & 0,004 \\
\hline Кровотечение & 2,2 & 18 & 0 & 0 & 0,297 \\
\hline Смерть в стационаре & 6,3 & 52 & 14,6 & 7 & 0,027 \\
\hline
\end{tabular}

ЗАесь и в табл. 8: ОНМК - острое нарушение мозгового кровообращения.

Таблица 8. Неблагоприятные исходы в период пребывания в стационаре у пациентов с ИМ в сочетании с БАНПГ

\begin{tabular}{|c|c|c|}
\hline ИсхоА, \% & $\begin{array}{c}\text { «Новая» } \\
\text { БАНПГ }\end{array}$ & $\begin{array}{c}\text { «Старая» } \\
\text { БАНПГ }\end{array}$ \\
\hline «Новая» $\mathrm{CH}$ & 22,2 & 10,7 \\
\hline Отек мегких & 20,6 & 3,6 \\
\hline Кардиогенный шок & 15,87 & 7,1 \\
\hline Смерть в стационаре & 17,5 & 14,3 \\
\hline
\end{tabular}

зе, стволового поражения $\Lambda$ КА, по Аанным коронарографии, не показали достоверности в качестве преАикторов неблагоприятного прогноза. Следует отметить, что БАНПГ не вошла в число предикторов, хотя ее наличие повышало риск смерти почти в 1,6 раза.

По результатам многофакторного регрессионного анализа Кокса, независимыми факторами неблагоприятного прогноза остались необходимость проведения ИВ $\Lambda$,

Таблица 9. Факторы, ассоциированные с неблагоприятным прогнозом у больных с ИМ в сочетании с БАНПГ (регрессионный анализ)

\begin{tabular}{|c|c|c|c|c|c|c|}
\hline Показатемь & Beta & SE & t-value & $\begin{array}{c}\text { Exponent } \\
\text { Beta }\end{array}$ & Wald & $\mathbf{p}$ \\
\hline Кıасс по Killip & 0,73 & 0,16 & 4,48 & 2,07 & 20,03 & $<0,0001$ \\
\hline Постоянная МА & 1,20 & 0,37 & 3,27 & 3,34 & 10,66 & 0,001 \\
\hline Периферический атероскмероз & 1,04 & 0,41 & 2,53 & 2,83 & 6,38 & 0,012 \\
\hline ХПН, анамнез & 1,23 & 0,50 & 2,48 & 3,43 & 6,15 & 0,013 \\
\hline ЧСС, 2-е сутки & 0,02 & 0,01 & 2,39 & 1,03 & 5,70 & 0,017 \\
\hline ИВ $\Lambda$ & 2,53 & 0,33 & 7,78 & 12,61 & 60,47 & $<001$ \\
\hline Прессорные препараты в первые 24 ч & 1,55 & 0,44 & 3,53 & 4,72 & 12,48 & 0,0004 \\
\hline Прессорные препараты посме 24 ч & 1,30 & 0,46 & 2,83 & 3,69 & 8,02 & 0,0046 \\
\hline
\end{tabular}

Таблица 10. Независимые факторы неблагоприятного прогноза в стационаре у больных ИМ в сочетании с БАНПГ

\begin{tabular}{|c|c|c|c|c|c|c|}
\hline Показатемь & Beta & SE & t-value & $\begin{array}{c}\text { Exponent } \\
\text { Beta }\end{array}$ & Wald & $\mathbf{p}$ \\
\hline ИВ $\Lambda$ & 2,04 & 0,50 & 4,05 & 7,66 & 16,40 & $<0,0001$ \\
\hline Прессорные препараты в первые 24 ч & 1,93 & 0,52 & 3,73 & 6,90 & 13,92 & $<0,0001$ \\
\hline ЧСС на 2-е сутки & 0,04 & 0,01 & 2,97 & 1,04 & 8,80 & 0,003 \\
\hline Прессорные препараты после 24 ч & 1,37 & 0,54 & 2,54 & 3,92 & 6,43 & 0,011 \\
\hline
\end{tabular}


потребность в прессорных препаратах в первые 24 ч и в последующем, а также ЧСС на 2-е сутки (табл. 10).

\section{ОбсужАение}

Согласно современным рекомендациям, все пациенты с «новой» БАНПГ Аолжны рассматриваться как имеющие шанс на проведение реперфузионной терапии. ОАнако регистр РЕКОРА-3, как и его преАшественники и многие Аругие исслеАования, продемонстрировал низкую вероятность проведения реперфузии на фоне БАНПГ, и прежАе всего, немеАменного направмения пациента в рентгеноперационную $[4,7,10]$.

Более того, наличие БАНПГ на ЭКГ вводимо в затруАнение врачей уже на Аогоспитальном этапе - эти пациенты достоверно реже получали адекватную медикаментозную терапию (кмопидогрел, АСК, $\beta$-аАреноблокаторы). В последующем, уже при госпитализации, у значительного числа пациентов был установлен диагноз ОКСбпST, что является оАним из наиболее серьезных недостатков в существующем подходе к ведению пациентов с ИМ на фоне БАНПГ. Именно оценка изменений на первой зарегистрированной ЭКГ явмяется принципиальной, так как определяет Аальнейшую тактику ведения пациента. И в этом отношении практически ничего не изменилось с момента проведения регистров РЕКОРА и РЕКОРА-2, когАа мы выдеАили несколько причин [4]. В первую очередь - это отсутствие Аостоверных критериев на ЭКГ ишемии на фоне БАНПГ, в том числе универсальных критериев Sgarbossa, активно обсуждавшихся в 90-е годы прошлого века [11]. Затем невозможность использовать оценку биохимических маркеров некроза из-за риска существенной задержки выбора тактики ведения пациентов, и неинформативность ЭхоКГ из-за асинхронного сокращения сегментов $\Lambda Ж$ вслеАствие самой БАНПГ. Таким образом, общеизвестные универсальные критерии ИМ неприменимы у большинства пациентов с БАНПГ.

Результаты проведенного анализа регистра РЕКОРА-3 вновь подтвердили высокий (более чем в 2 раза) риск смерти в стационаре у пациентов с ИМ на фоне БАНПГ. Кроме того, у таких пациентов значительно повышен риск возникновения и Аругих неблагоприятных исходов «новой» $\mathrm{CH}$, отека мегких, карАиогенного шока.

Вместе с тем, по Аанным регрессионного анализа, предикторами неблагоприятного исхода оказались не наличие Б $\Lambda$ НПГ, а тяжесть ИМ (класс по Killip, необходимость в ИВА и инотропной подАержке) и наличие множества сопутствующих заболеваний (мерцательная аритмия, поражение периферических артерий, ХБП). Следует также подчеркнуть, что пациенты с Б $\Lambda$ НПГ оказались достоверно старше. В этом ключе наши данные согласуются с результатами исследования швеАских кол- мег, показавших, что пациенты с ИМ с БАНПГ имеют большее количество сопутствующих заболеваний и высокий риск смерти в течение 1-го гоАа [9].

\section{Закмючение}

Таким образом, высокая метальность больных ИМ, вкАюченных в российский регистр ОКС РЕКОРА-3, на фоне блокады мевой ножки пучка Гиса обусловлена не просто наличием на ЭКГ блокаАы мевой ножки пучка Гиса, а более старшим возрастом, тяжестью состояния при поступлении и большим количеством сопутствующих заболеваний. Вместе с тем в связи с большим количеством ошибок на всех этапах ведения больных ИМ на фоне блокаАы мевой ножки пучка Гиса, возможно, целесообразно расширение видов ОКС (не только с подъемом и без подъема сегмента ST), а, например, с наличием блокаА ножек пучка Гиса (отдельно мевой и правой), депрессией сегмента ST, нормальной электрокардиограммы и Ар.

\section{* Список участников регистра «РЕКОРА-3»}

БАРНАУА: РуАакова А., Сукманова А., Бочарова А., Бубнова Е., Рогачева К., Гатальский К., Максакова Е., Фролова Ф., Бессонова А., Нечаева А., Павличенко О., Танана О., Харитонова Я., Вялова И,. Аисоченко А.; ВАААИМИР: Панин А., Наумчик А., Фомин Ю., Саверова Ю.; ВОРОНЕЖ: Шевченко И., БуАяк В., Елистратова О., Исламов Р., Костюков О., Козьмин М., Сафонов А., Федотов О., Фетисов Е., Филиппских А., Амитренко С., Испирьян А., Бородинова И., Ермилова М., Подрезова М.; ВЫСЕАКИ: Святенко О., Солоп И.;

АИНСКАЯ: Сергачева И., Баркова А., Аенисенко Е., Барков П.; ЕЙСК: Костюковец Р., Семенюта Е., Мурашко Е., Щеглова Т., Савенко А.; КАЗАНЬ: Галявич А., Мухаметгатова А., Балеева $\Lambda$. КААИНИНГРАА: МеАвеАев А., Аанилов В., Шарохина Т.; КАНАЕВСКАЯ: Жукова А., Рокотянская Е., Белов А.; КЕМЕРОВО: Барбараш О., Кашталап В., Тавцуева Е., Печерина Т., Федорова Н., Кочергина А., Чичкова Т., Андрозянова А.;

КРАСНОААР: Космачева Е., Сокаева 3., Макухин В., Круберг А., Рафф С., Кижватова Н., Прасолова С., Бабаян В., Волощенко М., Гинтер Ю., Веселенко М., Мерзмякова С.

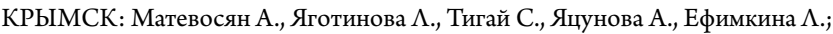
КУЩЕВКА: Гиниятова М., Терновая С., Москаленко $\Lambda . ;$

ААБИНСК: Исаева Н., Щербинина Е., Русов А.; $\Lambda$ ЮБЕРЦЫ: Гинзбург М., Мешкова Е.;

МОСКВА: Гимяров М., Новикова Н., Чепкий А., Нестеров А., Константинова Е., Ткаченко К., Козуб А., Семакина С., Тарасенко С., Зацаринная Е., Грачева Е.; НИЖНИЙ НОВГОРОА: Починка И., Ботова С., ГвозАулина М.;

ОАИНЦОВО: Харченко М., ШарафутАинова А.;

ОМСК: Ситников Г., Корсаков М., Пивень С.

ОРЕНБУРГ: Виноградова О., Захаров С., Аружинина А.;

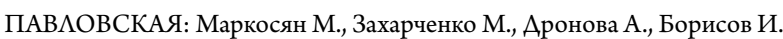

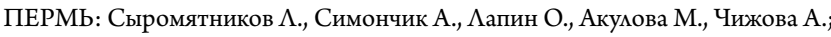
ПОЧИНКИ: Шептунов О., Гагаев А., Быстрова Н.; 
ПСКОВ: Калашников С., Кудрявцева О., Шапошников А., Семенова О., Романова Н.;

САМАРА: Аупияков А., Скуратова М., ГАинина Е., Ахматова Ю., Аоцманова Е., Габерман О., Ааникова Е., Рубаненко О., Андреева С.; САНКТ-ПЕТЕРБУРГ: Костенко В., Скородумова Е., Федоров А., Сиверина А.; СОЧИ: Бочманова Ю., Зыков М., Смагин И., Селиванова Н., Мартиросян Е.; СЫЗРАНЬ: Мирошник Е., Якунин А., Мендель Я., Анисимова А., Антонова М., Кузьмина Н.;

ТААЬМЕНКА: Наренкова С., Ковалева О.
ТАРУСА: Охотин А., Осипов М., Осипов В.;

ТВЕРЬ: Алексеев А., Разыграев Р., Шехаб А., Яковлева М.;

ТИХОРЕЦК: Свистунов М., Циганет $\Lambda .$, Гончаров В.;

ТОАьяТТИ: Пухова А., Карбузов М.;

ТОМСК: Марков В., Сыркина А., Белокопытова Н.;

ТУАПСЕ: Киселев А., Поправко А.;

УААН-УАЭ: Аонирова О., Сультимова И., Новокрещенных О.;

УСТЬ-ААБИНСК: Туник Е.;

ЧИТА: Аарева Н., Романова Е., ХиуАнев С., Маришкина К., Абрамова $\Lambda$.

\section{Сведения об авторах:}

Аупмяков А. В. - А.М.Н., Аоцент, зам. гл. врача ГБУЗ «Самарский областной клинический карАиологический Аиспансер» МинзАрава РФ, Самара; проф. кафеАры кардиологии и кардиохирургии ИПО ФГБОУ ВО «Самарский госуАарственный меАицинский университет» Минзарава РФ, Самара.

ФГБУ «Федеральный научно-клинический центр физико-химической медицины» ФМБА России, Москва

Эрлих А.А. - А.м.н., ст. н.с. маборатории клинической карАиологии.

ГБУЗ «Самарский областной клинический карАиологический Аиспансер» МинзАрава РФ, Самара

Ажинибалаева Ж.В. - врач-кардиолог.

\section{ФГБОУ ВО «Саратовский госуАарственный медицинский университет им. В. И. Разумовского» МинзАрава РФ, Саратов}

Отдел продвижения новых кардиологических информачионных технологий НИИ кардиологии

Киселев А.Р. - А.М.Н., веА.н.с. отдела.

Посненкова О.М. - к.м.н., ст. н.с. отАела.

E-mail: duplyakov@yahoo.com

\section{Information about the author:}

Samara State Medical University, Samara, Russia

Dmitry V. Duplyakov - MD, professor.

E-mail: duplyakov@yahoo.com

\section{МИТЕРATУPA/REFERENCES}

1. 2009 Focused Updates: ACC/AHA Guidelines for the Management of Patients With ST-Elevation Myocardial Infarction (Updating the 2004 Guideline and 2007 Focused Update) and ACC/AHA/SCAI Guidelines on Percutaneous Coronary Intervention (Updating the 2005 Guideline and 2007 Focused Update). A Report of the American College of Cardiology Foundation/American Heart Association Task Force on Practice Guidelines. Circulation 2009;120:2271-2306.

2. Gunnarsson G., Eriksson P., Dellborg M. Continuous ST-segment monitoring of patients with left bundle branch block and suspicion of acute myocardial infarction. J Int Med 2004;255:571-578.

3. Duplyakov D. V., Khokhlunov S. M., Tukhbatova A.A. et al. Acute coronary syndrome with ST segment elevation: the possibility of a hospital register. Cardiology and cardiovascular surgery 2010;4:27-31. Russian (Аупмяков А.В., Хохиунов С. М., Тухбатова А.А. и Ар. Острый коронарный синдром с подъемом сегмента ST: возможности госпитального регистра. КарАиология и серАечно-сосудистая хирургия 2010;4:27-31).

4. Lotina A. S., Duplyakov D. V., Erlikh A. D. Prognostic value of left bundle branch block in patients with acute coronary syndrome. Cardiology 2013;7:35-39. Russian (Аотина А.С., Аупияков А. В., Эрлих А.А. Прогностическое значение блокады мевой ножки пучка Гиса у пациентов с острым коронарным синдромом. Кардиология 2013;7:35-39).

5. Hassi M., Kunstmann S., Corbalán R. et al. Intraventricular conduction disorders in acute myocardial infarction: early and late clinical significance. Rev Med Chil 1989;117:1381-1386.
6. Shlipak M. G., Go A. S., Frederick P.D. et al. Treatment and outcomes of left bundle-branch block patients with myocardial infarction who present without chest pain. National Registry of Myocardial Infarction 2 Investigators. JAm Coll Cardiol 2000;36:706-712.

7. Guerrero M., Harjai K., Stone G. W. et al. Comparison of the prognostic effect of left versus right versus no bundle branch block on presenting electrocardiogram in acute myocardial infarction patients treated with primary angioplasty in the primary angioplasty in myocardial infarction trials. Am J Cardiol 2005;96:482-488.

8. Melgarejo-Moreno A., Galcerá-Tomás J., Consuegra-Sánchez L., et al. Relation of New Permanent Right or Left Bundle Branch Block on Short- and Long-Term Mortality in Acute Myocardial Infarction Bundle Branch Block and Myocardial Infarction. Am J Cardiol 2015; 116:1003-1009.

9. Stenestrand U., Tabrizi F., Lindbäck J. et al. Comorbidity and myocardial dysfunction are the main explanations for the higher 1-year mortality in acute myocardial infarction with left bundle-branch block. Circulation 2004;110:1896-1902.

10. Wong C.K., Stewart R.A., Gao W., et al. Prognostic differences between different types of bundle branch block during the early phase of acute myocardial infarction: insights from the Hirulog and Early Reperfusion or Occlusion (HERO) - 2 trial. Eur Heart J 2006;27:21-28.

11. SgarbossaE. B.,PinskiS. L.,BarbagelataA.et al.Electrocardiographic diagnosis of evolving acute myocardial infarction in the presence of left bundle-branch block. N Engl J Med 1996;334:481-487.

Поступима 05.08.16 (Received 05.08.16) 